\title{
\#nasbordasabertasdeumtweet:
}

\section{pedagogias e produção de microcontos no Twitter}

\author{
\# nasbordasabertasdeumtweet: \\ pedagogies and production of micro-stories on Twitter
}

\#nasbordasabertasdeumtweet:

pedagogias y producción de microhistoria en Twitter

RAPHAELLE NASCIMENTO SILVA (Da

Edvaldo SOUZA COUTO (Db

\section{Resumo}

A produção de microcontos no Twitter se inscreve dentro de uma prática social de escrita de maior espectro - a twitteratura. Neste contexto, a partir dos estudos e das interfaces que aproximam a Educação da Literatura na Cibercultura, o artigo apresenta resultados de uma pesquisa que teve o objetivo de analisar a produção de microcontos no Twitter, destacando as pedagogias de escrita ali desenvolvidas. O método usado foi o qualitativo, de cunho analítico e interpretativo. Para a análise dos dados usou-se a técnica de Análise Textual Discursiva - ATD e princípios da Análise de Redes Sociais - ARS. O argumento central é que a twitteratura é uma pedagogia da escrita em rede que se constrói, principalmente, através da experiência compartilhada e da mobilização on-line de aprendizagens. O artigo conclui que uma das formas de produção das culturas contemporâneas é a escrita literária em rede, a qual se utiliza da construção e da mobilização de pedagogias que contribuem para a circulação de modos de ser e de formas de compartilhar conteúdos estéticos.

\footnotetext{
a Instituto Federal de Educação, Ciência e Tecnologia da Bahia (IFBA), Campus de Barreiras, BA, Brasil. Doutora em Educação, e-mail: raphaelle.ns.22@gmail.com b Universidade Federal da Bahia (UFBA), Salvador, BA, Brasil. Doutor em Educação, e-mail: edvaldo@ufba.br
} 
Palavras-chave: Twiteratura. Microcontos. Twitter. Educação e Literatura. Cibercultura.

\begin{abstract}
The production of micro-stories on Twitter is part of a broader social writing practice the twitterature. In this context, from the studies and interfaces that approximate Education to Literature in Cyberculture, these article presents the results of an investigation that aimed to analyze the production of micro-stories on Twitter, highlighting the writing pedagogies developed. The research method was qualitative, analytical and interpretive. The data analysis was based on the Discursive Textual Analysis (DTA) technique and the principles of Social Network Analysis - ARS. The central argument is that twitterature is an online writing pedagogy that is built mainly through shared experiences and the mobilization of online learnings. The article concludes that online literary writing is one of the forms of production of contemporary cultures, which uses the construction and mobilization of pedagogies that contribute to the circulation of ways of being and ways of sharing aesthetic content.
\end{abstract}

Keywords: Twitterature. Micro-stories. Twitter. Education and Literature. Cyberculture.

\title{
Resumen
}

La producción de microcuentos en Twitter se inscribe en una práctica social de escritura más amplia - la twitteratura. En este contexto, a partir de los estudios e interfaces que aproximan la Educación a la Literatura en la Cibercultura, el artículo presenta resultados de una investigación que tuvo como objetivo analizar la producción de microcuentos en Twitter destacando las pedagogías de escritura allí desarrolladas. El método utilizado fue de tipo cualitativo, analítico e interpretativo. Para el análisis de datos se utilizó la técnica de Análisis Textual Discursivo (ATD) y los principios del Análisis de Redes Sociales - ARS. El argumento central es que twitteratura es una pedagogía de escritura en red que se construye, principalmente, a través de la experiencia compartida y la movilización de aprendizajes en línea. El artículo concluye que una de las formas de producción de las culturas contemporáneas es la escritura literaria en red, que utiliza la construcción y movilización de pedagogías que contribuyen a la circulación de formas de ser y formas de compartir contenidos estéticos.

Palabras clave: Twitteratura. Microcuentos. Twitter. Educación y Literatura. Cibercultura. 


\section{Introdução}

A produção de microcontos no Twitter se inscreve dentro de uma prática social de escrita de maior espectro - a twitteratura. Nela, além dos aspectos diretamente relacionados aos gêneros ou às formas literárias eleitas pelos usuários em suas experimentações estéticas, vemos a adoção de um espaço, de um meio, de uma mídia social como um lugar legitimado para abrigar literatura. No entanto, o que o Twitter oferece aos sujeitos que dele decidiram fazer um uso literário, autorizado pela interação, pela forma mais distribuída de se relacionar com os produtos culturais na cibercultura, é um espaço de remediação, uma remodelagem das linguagens das mídias que o precederam. Esse espaço é repleto de pedagogias ${ }^{1}$ sobre a produção, difusão e leitura dos microcontos.

É nesse contexto que este artigo apresenta o resultado de uma pesquisa sobre pedagogias e produção de microcontos no Twitter. O objetivo do artigo foi analisar a produção de microcontos no Twitter, destacando as pedagogias de escrita ali desenvolvidas. O método usado foi o qualitativo, de cunho analítico e interpretativo. Para a análise dos dados foram usadas a técnica de Análise Textual Discursiva ATD e princípios da Análise de Redes Sociais - ARS. As análises foram desenvolvidas em torno de três eixos: os perfis, os microcontos e as suas repercussões. O argumento central é que a twitteratura, a produção literária no Twitter, é uma pedagogia da escrita em rede que se constrói, principalmente, através da experiência compartilhada e da mobilização on-line de aprendizagens. O artigo conclui que uma das formas de produção das culturas contemporâneas é a escrita literária em rede, a

\footnotetext{
${ }^{1}$ Pedagogia é a ciência que estuda a educação, o ensino e a aprendizagem. Pedagogia é um conjunto de métodos que assegura a formação, formal ou informal, dos indivíduos. Neste artigo, usamos o conceito pedagogia, no singular ou no plural, para nos referirmos, sobretudo, às orientações que circulam nas escolas, mas também nos dispositivos culturais, nas conexões das redes digitais, explícitas ou não, que ajudam a moldar comportamentos, desenvolver atitudes, construir modos de ser. A partir deste entendimento, também ressaltado por autores como Louro (2018), Silva (2014) e Couto (2012), nosso argumento é que os modos como as pessoas escrevem, leem, curtem, retuitam e comentam microcontos no Twitter orientam outras pessoas a escreverem e lerem a twitteratura, por exemplo, nesta plataforma de rede social. Esses procedimentos são repletos, portanto, dessas pedagogias, que modulam ensino e aprendizagem e que são típicas do nosso contexto cultural.
} 
qual se utiliza da construção e da mobilização de pedagogias que contribuem para a circulação de modos de ser e de formas de compartilhar conteúdos estéticos.

\section{\#literaturanotwitter.280 caracteres para microcontar o mundo}

A literatura abarca uma infinidade de caminhos possíveis de representação. Nela se conectam vários elementos constitutivos da dimensão humana os quais são recriados, mimeticamente, e encontram, nas redes sociais da internet, a exemplo do Twitter, possibilidades para leitura, produção e disseminação. Nesse sentido, a literatura é um fenômeno artístico-cultural, um elemento constituinte da cultura, que também se transforma em seus processos de composição e criação diante da cibercultura e de sua produção e disponibilização no ciberespaço. Assim sendo, a twitteratura é uma de suas faces, a qual revela comportamentos, estratégias e aprendizagens distintas que são acionadas na produção intencional de textos literários no Twitter, a exemplo dos microcontos, constituindo-se como uma pedagogia.

A variedade de áreas que vêm tomando o Twitter como objeto de estudo nas mais diversas perspectivas e abordagens denota sua fertilidade no que diz respeito à capacidade de expor, tornar visível, as redes sociais da internet que o perpassam e nele se constroem de forma singular, dada a sua arquitetura única (MONTIEL, 2015). O Twitter prima pela instantaneidade e se estrutura pela brevidade e concisão. Tais características requerem, para sua sobrevivência e replicação, uma habilidade de composição do discurso atenta a vários elementos peculiares ao universo da rede e à limitação inicial dos 140 caracteres, a qual foi expandida pelos criadores da plataforma para 280, em 2017. Sua estruturação de microblog, como propõe Montiel (2015), ou sua natureza de microdesing de ideias, conforme Santaella e Lemos (2010), ou ainda a sua natureza de micromensageiro, como prefere Recuero (2011) e Recuero e Zago (2010) imprime na essência de suas produções comunicativas o princípio da economia linguística com o máximo de riqueza potencial do texto. Nesse sentido, constrói, em sua rede de possibilidades, mecanismos que funcionam como alargadores comunicacionais a serem explorados para a melhor composição do tweet, nome atribuído às postagens nessa rede. 
A imersão no Twitter constrói experiências muito distintas de outras plataformas também muito populares como o Facebook, por exemplo. Ao contrário dos demais sites de redes sociais, os laços construídos no Twitter, visíveis através dos rastros e pistas digitais deixadas pelos sujeitos através dele, não se estabelecem em função de um vínculo afetivo, mas pelos interesses em determinados conteúdos e suas estratégias de produção. Esse diferencial gera também a necessidade de construir caminhos e pedagogias distintas para a manutenção, a ampliação e a criação de visibilidade, posto que a produção dos conteúdos é o que está em evidência e sustenta as conexões formadas nessa rede, conforme Recuero (2011) e Santana (2014).

As redes sociais da internet interferem na maneira como os sujeitos se conectam e agem em suas relações para além da internet. No entanto, o contrário também acontece, posto que esta seja uma via de autorregulação constante. As tecnologias digitais estruturam a sociedade e são por ela estruturadas o tempo todo. Nesse sentido camaleônico, o Twitter foi escolhido, neste estudo, em função da produção literária que nele ocorre, pois acreditamos que nela se manifestam aspectos pedagógicos distintivos da escrita interativa em rede.

Dialogamos, dessa maneira, com Santana e Couto (2017), os quais sinalizam que, nesse ambiente, a visibilidade mediada tem uma amplitude no que se refere ao alcance, visto que permite tornar visíveis acontecimentos, fatos, opiniões em diferentes espaços e tempos, bem como, de acordo com o nosso foco de estudo, dá visibilidade às produções estéticas, sobretudo, as literárias. A volumosa produção literária que tem sido feita nesse ambiente, seja como poesia, aforismo, microconto, é ilustrativa da apropriação que os sujeitos fazem dessa plataforma de rede social para fins diversos, o que inclui as postagens de conteúdo literário. Concordamos com Marcuschi (2005, p. 20) quando afirma que "[...] os gêneros textuais são frutos de complexas relações entre um meio, um uso e a linguagem".

A cibercultura, entendida como a infraestrutura tecnológica e os comportamentos das pessoas conectadas (LÉVY, 1997), está promovendo, no que se refere à produção literária, uma espécie de movimento de democratização, análogo ao que ocorreu durante o século XIX com a publicação do romance em folhetins. Enquanto esse movimento histórico representou para a literatura sua democratização 
"em virtude de seu reconhecimento em camadas sociais e em culturas bem diversas" (LIMA, 2016, p. 193), a produção literária nas redes sociais da internet, a exemplo do Twitter, tem permitido o redimensionamento dos processos oficiais e institucionalizados de produção literária, desde sua concepção à distribuição editorial dos bens culturais, perpassando pelos filtros e legitimações editoriais. O percurso de produção da literatura tem ganhado também outros trajetos.

Nesse ínterim, como afirma Oliveira (2016, p. 205), "numa relativa distância desses espaços institucionais mais ortodoxos, hoje se multiplicam as fontes de legitimidade cultural, com o comparecimento de outras vozes, discursos, autorias e leituras que reivindicam o exercício e o estatuto da literatura também”. Dentre as novas fontes dessa legitimidade, estão as redes sociais da internet que permitem aos sujeitos almejarem o espaço de autoria e produção literária, o que nos põe em concordância com a autora ao pensarmos que "nunca se promoveu tanto a literatura como se faz agora nessa mídia. Território da linguagem, da palavra escrita, principalmente, o suporte digital promove vida longa para a escritura nas mãos de usuários ocasionais ou de internautas de plantão" (OLIVEIRA, 2016, p. 206). Os sujeitos ocupam as redes e preenchem seus comportamentos com aprendizagens online e pedagogias próprias de leitura e escrita estética do mundo.

Ao pensarmos na relação entre literatura e cibercultura, nos deparamos com o fato de que estas têm uma natureza próxima (SAGREDO, 2012). A conexão em rede e a digitalização podem amplificar elementos presentes na natureza estética do literário. Esse movimento, por sua vez, pode gerar comportamentos de leitura e escrita que evidenciam uma importante tendência da vida literária na cibercultura, a qual seja “a exposição dos processos de criação artística em circuitos midiáticos, constituindo experiências de cumplicidade intelectual e de colaboração solidária com os pares" (OLIVEIRA, 2016, p. 210). Essa produção literária de caráter mais movente é fruto da dinâmica relação entre os produtos estéticos e os elementos de cultura historicamente situados.

Conforme Bakhtin (2010, p. 360) “a Literatura é parte inseparável da cultura, não pode ser entendida fora do contexto pleno de toda uma época”. Nesse sentido, as produções literárias elaboradas no Twitter se revelam como produtivas também para 
o campo da Educação, uma vez que entendemos essa área de conhecimento e de estudo em seu sentido mais amplo. Nessa perspectiva, os comportamentos, as subjetividades, as aprendizagens estéticas, em rede, também se configuram como formas de educar as sensibilidades, de alimentar a produção do conhecimento e ampliar as redes de construção de saberes. Os comportamentos traduzem e exteriorizam pedagogias de produção, compartilhamento e uso de tecnologias educacionais, dentre as quais se encontra a produção literária em rede.

$\mathrm{Na}$ twitteratura, forma de produção escrita com fins estéticos dentro do Twitter, os sujeitos, ao se autorizarem a criar e compartilhar de forma conectada suas micronarrativas, também se inserem em um processo movente de interação e descobertas que mobilizam muitas estratégias para o ato de narrar. O Twitter, para além da ágora digital, a qual mobiliza uma diversidade de conteúdos e comportamentos, se apresenta como ambiente em que se aprende, se troca informações e experiências. Nele são mobilizadas estratégias de produção estética de conteúdo de forma intencional e autorizada, construindo pedagogias próprias (COUTO, 2014).

Em contato com outros sujeitos e através da conexão e compartilhamento, a experiência de narrar se exterioriza, revelando estratégias, vivências e processos de criação e aprendizagem estética. Na twitteratura, os sujeitos, ao mesmo tempo em que narram o outro, aprendem sobre si e exteriorizam essas aprendizagens através das redes sociais digitais.

\section{\#desenhometodologico: a construção da pesquisa}

Esta é uma pesquisa qualitativa, de cunho descritivo, analítico e interpretativo (CRESWELL, 2010). Nela estudamos um recorte da relação entre a rede social Twitter, seu campo empírico, e a produção literária de microcontos. Para tanto, selecionamos 12 perfis do Twitter produtores de micronarrativas. O processo de seleção foi iniciado através da utilização da hashtag \#microconto na ferramenta de busca da plataforma com o intuito de localizar tweets associados ao conteúdo literário em foco.

Esse procedimento nos levou às publicações de 113 perfis, mas nem todas as postagens apresentavam micronarrativas no corpo dos tweets. Em muitos casos, 
tratava-se de divulgações de outros perfis produtores de microcontos, de concursos, de páginas em outros espaços em rede, isto é, conteúdos relacionados à produção de micronarrativas, mas nem sempre com a publicação dos textos. Para chegar aos perfis efetivamente produtores de micronarrativas foi necessária a diminuição desse volume de informação.

Realizamos, então, a visitação aos 113 perfis identificados e estabelecemos três elementos da composição dos perfis a serem considerados: a) a biografia inserida por cada usuário ao criar o seu perfil; b) a composição do seu nome de usuário — username; e c) a foto de perfil e/ou capa utilizada. A partir da observação desses aspectos, procuramos elementos textuais, visuais e/ou discursivos que apontassem indícios relacionados ao uso literário das contas. Ficamos atentos a usernames elaborados a partir de referências à ação de escrita, as imagens de perfil ou capas que construíssem relações metalinguísticas com a produção literária ou ainda a declarações explícitas ou implícitas desse tipo de atividade no texto das biografias.

As informações levantadas durante essa visitação permitiram diminuir o número de perfis para 32. Com esse novo cenário, por um período de três meses, compreendidos entre abril e junho de 2017, se tornou possível adotar uma rotina de visitação diária a esses perfis para a observação das postagens. Nessa fase, definimos mais dois critérios: a) a presença de links na biografia que indicassem outros ambientes nos quais os sujeitos mantivessem escritas literárias, sendo essas de microcontos ou outros gêneros, mas que demonstrassem uma intencionalidade estética em seus comportamentos em rede; e b) o aspecto relacional entre as contas, isto é, a identificação de que entre os perfis em observação houvesse conexões: a ligação de seguidor, menção, curtida ou retweet.

Essa etapa de aperfeiçoamento dos resultados da busca nos levou à seleção final de 12 perfis produtores de microcontos na rede social Twitter. Com essa definição, fizemos uso de um roteiro semiestruturado de observação e um diário de campo para proceder à observação encoberta. Segundo Lasta e Barrichello (2013, p. 53) essa técnica é um tipo de observação na qual “o pesquisador apenas observa o seu campo de estudo, sem que os sujeitos observados saibam que estão sendo estudados". Nela, prevemos a ausência de contato com os sujeitos observados durante a coleta 
das informações a fim de não provocar alterações nas suas práticas sociais habituais. Isso nos permite aproximar as informações produzidas durante o período da pesquisa de suas ocorrências naturais e despreocupadas com avaliações externas.

Para analisar as informações coletadas nos perfis selecionados consideramos as definições de Elm (2009) acerca da privacidade das contas e conteúdos em rede. De acordo com o autor "a privacidade diz respeito à integridade individual, sendo possível classificar os ambientes online em quatro níveis de privacidade" (ELM, 2009, p. 75). Dentre os quatro níveis — público, semipúblico, semiprivado e privado — destacamos o nível público, o qual se caracteriza como aberto e disponível a todos sem a necessidade de cadastro, convite ou aceitação, ou autorização direta. Todos os perfis do Twitter observados na pesquisa se caracterizam como públicos, bem como aqueles com os quais mantiveram interações nas imagens coletadas.

Os tweets analisados na pesquisa foram coletados considerando as publicações realizadas entre janeiro e dezembro de 2017 e, uma vez atingidos os objetivos de pesquisa relacionados à técnica da observação encoberta, os responsáveis pelos perfis observados foram contatados para tomarem ciência do estudo em andamento, das motivações da primeira fase da observação encoberta e da coleta das informações. Nesse momento foram convidados a colaborar com a pesquisa, autorizando o uso integral do material coletado, incluindo nome do perfil e foto, através do Termo de Consentimento Livre e Esclarecido - TCLE, o qual resguarda todos os cuidados éticos da pesquisa. No entanto, ainda assim, neste artigo, optamos por fazer menção aos perfis através de uma sequência numérica, de forma que os sujeitos são nomeados por uma sequência que vai de@perfil1 a@perfil12, evitando, assim, a identicação dos autores.

Para proceder à análise das informações, utilizamos a técnica de Análise Textual Discursiva - ATD (LUIJPEN, 1973; NAVARRO e DIAZ, 1994; ASSMANN, 1998; MORAES e GALIAZZI, 2016), no intuito de construir temas e/ou categorias de discussão que nos permitiram realizar uma leitura descritiva e interpretativa do fenômeno em estudo. De forma complementar, fizemos uso de princípios da Análise de Redes Sociais - ARS para mídia social, na qual buscamos inspiração (JONES, 1999; HINE, 2000; FREEMAN, 2004; AMARAL e 
MONTARDO, 2010; RECUERO, BASTOS e ZAGO, 2015). As análises foram desenvolvidas em torno de três eixos: os perfis, os microcontos e as suas repercussões. Eles estruturam a apresentação e discussão dos dados a seguir.

\section{\#personasemconstrução: realidades microcontadas no Twitter}

A produção literária em rede se configura como uma forma de os sujeitos imprimirem seus modos de ser e de estar na cibercultura. Ela revela comportamentos intencionais e direcionados, nos quais podemos perceber gestos de aprendizagens que promovem conteúdos estéticos variados. Nesse sentido, com o intuito de compreender as pedagogias presentes nas práticas de escrita literária no Twitter, apresentamos e analisamos os dados da pesquisa em três eixos que se complementam: os perfis, os microcontos e as suas repercussões.

\section{Os perfis}

Dentre os elementos que estruturam o perfil na rede social Twitter, estão: foto, biografia, username, links associados à conta e quantidade de seguidores. Esses aspectos, somados aos comportamentos de escrita, revelam-se como uma autoconstrução de identidades em rede, as quais são autorizadas pelas possibilidades ofertadas nos espaços digitais de remediação, o que é o caso do Twitter.

Essas informações nos permitem reconhecer como cada sujeito se apresenta em seu perfil e como elabora sua identidade digital no Twitter. Dentre os 12 perfis selecionados, nos quais observamos esses elementos de composição do perfil, notamos que 04 - @perfil3,@perfil6,@perfil7 e@perfil9 — se declaram e se reconhecem como escritores. Atribuem a essa prática associações de prazer e satisfação ao lado de outras atividades corriqueiras do dia a dia, como torcer por um time de futebol ou se reconhecer como fã de um gênero musical. Nesses perfis, a identidade escritora se amalgama às outras identidades várias que cada sujeito assume em suas relações e espaços sociais. Ela se caracteriza como um ato intencional de uso dessa rede, a qual se constitui através da conectividade always on, abrangendo "o fio 
invisível que se multiplica entrelaçando consciências, espaços e desejos" (SANTAELLA e LEMOS, 2010, p. 55).

Além disso, também destacamos o fato de que 2 desses perfis que se autodeclaram como escritores em suas biografias também manifestam essa intenção identitária na rede através de seus usernames, atrelando-os diretamente à ação de escrita:@perfil3 e @perfil7. Há também uma distinção em alguns desses perfis: o texto de suas biografias figura como uma espécie de declaração-manifesto da compreensão estética do perfil que constroem subjetivamente em rede. O@perfil7 apresenta-se como um perfil que utiliza a rede social Twitter para "significar a realidade urbana em 140 toques" através da produção de "poemas, contos e outras cositas más...”.O@perfil6 se apresenta como co-criador de um blog literário e colaborador de uma coluna literária, expandindo seus comportamentos de escrita para espaços distintos do Twitter, mas ainda expressos em rede.

Isso confirma o fato de que o imbricamento entre o universo digital e as relações interpessoais, bem como os processos de comunicação, segundo Gonzáles Gutiérrez (2018, p. 11, tradução nossa), "tem contribuído para entender a identidade não como centralizada nos limites de um assunto privado e individual, mas como um sentimento de colaboração, construção coletiva e formação de identidades em rede". O autor ainda acrescenta que, em função disso, integram "ao mesmo tempo experiências que construam modos alternativos de expressão, ligados à experiência relacional” (GONZÁLES GUTIÉRREZ, 2018, p. 11, tradução nossa).

Nessa mesma linha de expansão, 7 perfis atrelam sua conta no Twitter a links de outros espaços em rede, nos quais ampliam sua ação escritora: @perfil3, @perfil4, @perfil6,@perfil7,@perfil10,@perfil11 e@perfil12. Esse comportamento confirma a ideia de que, embora os mecanismos de sua interface sejam lineares, o ciberespaço em si mesmo não o é (SANTAELLA e LEMOS, 2010). Ao seguirmos os links deixados nos perfis, encontramos outros espaços e faces da identidade digital escritora desses sujeitos que amplificam as dobras de sua imersão na cibercultura e em comportamentos da cultura digital. Trata-se de extensões hipertextuais dos sujeitos, como propõe Lévy (2003) em sua analogia entre o pensamento humano e o 
hipertexto, que dilatam sua presença por diferentes ambientes e fazem neles usos expressivos das possibilidades ofertadas em rede.

Assim, em um detalhamento dessas experiências, identificamos comportamento em rede que perpassa por vários objetivos e formas de produção de conteúdo. O@perfil3 associa à conta do Twitter o link para um blog pessoal, no qual o principal conteúdo produzido é a experimentação literária através de textos de diversos gêneros, livres de preocupação classificatória. No link inserido pelo@perfil4, encontramos uma conta no Tumblr com produção de textos poéticos. O@perfil6 nos leva a navegar por seu blog pessoal, no qual encontramos uma variedade de materiais autorais como contos, crônicas, microcontos, ensaios e notas sobre temas diversos, quadrinhos, tiras e ilustrações.

Através do link no@perfil7 nos conectamos a uma página pessoal com produção de conteúdo literário e produções variadas acerca de política, entretenimento e relatos. A conta de @perfil10 traz o link para um blog de publicação e debate de textos associados a temas como cultura, leitura e educação, no qual faz aos visitantes um convite à interação naquilo que intitula como sendo um consultório linguístico. No link indexado pelo@perfil11, nos deparamos com uma página pessoal na qual várias abas se expandem e podemos navegar por seus livros publicados, produção acadêmica, trabalhos de revisão, crônicas e outras produções textuais de conteúdo variado. Por fim, o @perfil12 aponta a indexação do link para a sua conta em outra rede social — o Instagram — e neste apresenta outros interesses pessoais nos conteúdos produzidos, distintos da produção literária feita no Twitter.

Esse mapeamento nos permite inferir que a maioria dos perfis pesquisados 7 de 10 - mantém um comportamento em rede consistente e conectado a vários ambientes e usos. Além disso, essas informações apontam que seus comportamentos não se limitam a uma única plataforma, conteúdo ou interesse. Os elementos de composição desses perfis no Twitter e suas conexões revelam sujeitos imersos na cibercultura e conscientes das possibilidades de produção, compartilhamento, indexação e ampliação de conteúdos que as mídias digitais oferecem em diversas formas. Ao demonstrarem essa consciência, os sujeitos também exteriorizam, em seus conteúdos, formas específicas de produção, estratégias e aprendizagens que são 
acionadas para alcançar os objetivos. Eles percebem esses espaços como um artefato social no qual se aprende e que "passa de um plano de criação a um recurso de reconstrução da identidade, ampliada pela criação e interação com outros usuários de uma rede" (GONZÁLES GUTIÉRREZ, 2018, p. 12, tradução nossa).

Há nesse comportamento uma consciência estético-pedagógica formada que compreende o espaço da rede social como fértil e produtivo para a criação de um tipo de literatura específica, pautada, sobretudo, em estratégias e aprendizagens relacionadas à brevidade e à captura do real, do cotidiano. Os perfis que se declaram como escritores em suas biografias colocam como intersecção entre a arte literária e a rede social em questão elementos como: a limitação de espaço, a moldura urbana, a portabilidade e a abreviação. Além disso, à medida que a observação dos perfis durante o período da pesquisa de campo foi se aprofundando, descobrimos a intersecção entre 3 dos 12 perfis:@perfil6,@perfil9 e @perfil10. Esses três perfis são integrantes de um coletivo de escritores citado na biografia do@perfilb. Esse é um aspecto significativo da identidade escritora desses sujeitos que se reconhecem em suas práticas sociais de escrita individual, mas também elaboram comportamentos coletivos em uma pedagogia colaborativa.

Também destacamos que 9 perfis possuem aspectos relacionais, ou seja, são seguidos ou seguidores em relação a outras contas do grupo selecionado: @perfil3, @perfil4,@perfil5,@perfil6,@perfil7,@perfil9,@perfil10,@perfil11 e@perfil12. Nessas conexões, o@perfill se destaca na quantidade de nós estabelecidos, é o que mais segue - 6 perfis - e o que é mais seguido - 4 perfis - dentro do grupo selecionado. Esse destaque é importante porque pode ser considerado um elemento indicativo tanto das interações na rede quanto da validação dos conteúdos produzidos, uma vez que “o uso específico do Twitter como recurso literário digital [...] permite pensar cada tweet como produto individual de criação (verso autônomo) que pode ser compartilhado, respondido, em consequência, possibilita novos intercâmbios entre os usuários" (GONZÁLES GUTIÉRREZ, 2018, p. 13, tradução nossa). Assim, quanto mais conexões, mais possibilidades de expansão dos conteúdos em rede. 
Por outro lado, a despeito dessa concentração destacada no@perfil9, podemos constatar que, no geral, as conexões dentro do grupo acontecem de maneira mais espalhada e dispersa e não necessariamente de forma recíproca. Esses dados nos permitem confirmar uma das naturezas distintas do Twitter em relação a outras redes sociais, a qual seja o fato de que as conexões não se dão por laços afetivos e/ou por bilateralidade (SANTAELLA e LEMOS, 2010).

Assim, se considerarmos que os laços apresentados repercutem um interesse em comum entre os sujeitos, isto é, a produção de microcontos, inferimos que essas conexões podem funcionar dentro do grupo como uma forma de validação dos conteúdos produzidos. Conforme os princípios da teoria de Análise de Redes Sociais, as conexões entre os nós são dados significativos para a compreensão das interações em rede.

Os dados apontados na compilação dos elementos de composição dos perfis pesquisados mostram uma variação que vai de 5 seguidores na conta de @perfil5 a 10,4 mil seguidores na conta de @perfil11. As conexões mapeadas dentro do grupo selecionado são importantes para ajudar na compreensão da constituição de suas identidades digitais. Já as métricas gerais no Twitter contribuem para que possamos visualizar com mais clareza e extensão as repercussões geradas por suas identidades em suas produções em rede.

Ao concluir o referencial analítico dos perfis selecionados, identificamos, em desalinho com os dados apresentados na maioria dos perfis, que 1 deles (@perfil5) não formula uma autobiografia para a rede social. Também constatamos que 5 perfis _@perfil2,@perfil4,@perfil10,@perfil11 e@perfil12_optam por marcar, em sua construção subjetiva de identidade, outros aspectos, tais como: profissão, formação acadêmica e generalidades, dentre as quais, pelas práticas cotidianas de suas postagens, se inserem as experimentações literárias. Essa leitura interpretativa dos dados se apresenta como um aspecto enriquecedor a ser considerado e discutido na análise conseguinte dos temas das produções observadas na pesquisa e de suas repercussões. 


\section{Os microcontos}

Os microcontos produzidos pelos perfis selecionados são uma marca atemporal da capacidade de representação do texto literário remediado. Eles revelam a resiliência e o caráter camaleônico da literatura como artefato cultural sociohistoricamente situado. Nos microcontos recolhidos nos perfis observados, identificamos 10 categorias temáticas dispostas conforme aparece no Gráfico 1.

\section{Gráfico 1 - Categorias Temáticas}

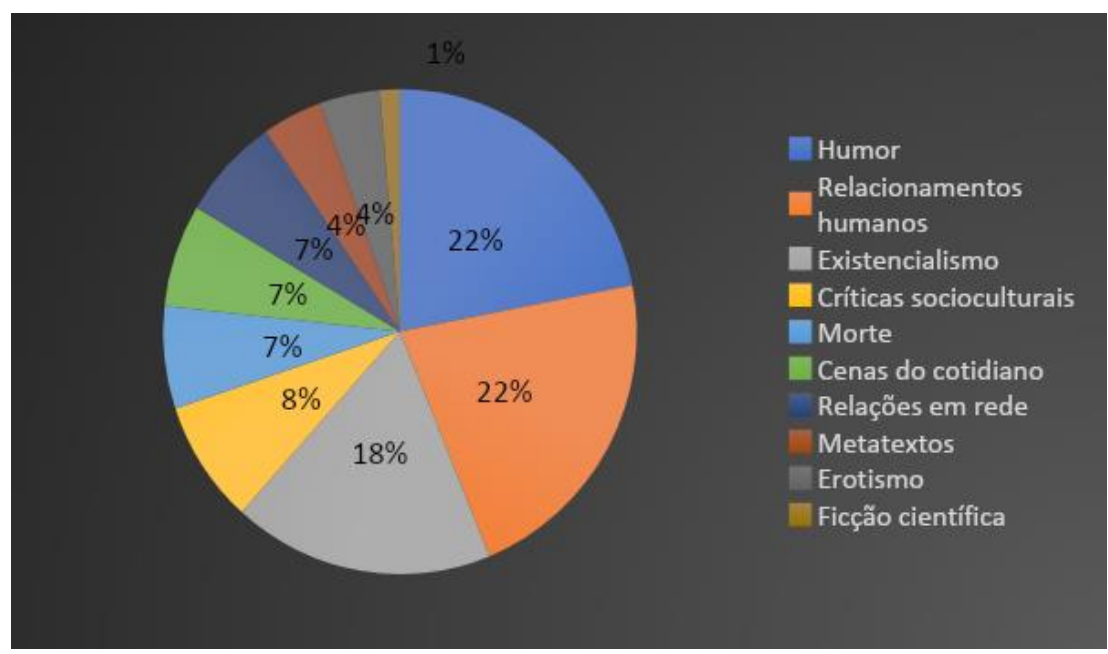

Fonte: Os autores do artigo e da pesquisa.

Os temas mapeados nas micronarrativas produzidas pelos perfis selecionados são atemporais na produção literária universal e dialogam com a questão motriz das postagens no Twitter: “O que está acontecendo?”, o que revela uma aprendizagem sobre o uso da rede. As categorias temáticas identificadas flertam com o tom prosaico da rotina e se misturam a outros tantos registros comuns que preenchem diariamente o fluxo movente dos tweets que têm vida curta e efêmera. No entanto, como uma espécie de estranhamento, de quebra da linguagem comum, esses temas trazem, nos microcontos, molduras e contornos estéticos que funcionam como uma pausa na realidade.

Os microcontos apresentam-se como narrativas ficcionais que capturam reações, sentimentos e relações humanas através da representação, caracterizando-se como textos literários. Eles nos permitem compreender que em "narrativas curtas, 
significados específicos são criados sobre realidades concretas da vida humana, sejam elas contadas através de mecanismos fictícios e auto-ficcionais, bem como reações a tweets como a expressão de sentimentos e sentimentos evocativos" (GONZÁLES GUTIÉRREZ, 2018, p. 22, tradução nossa).

A sistematização desses temas desenha os contornos de um mapa de representação estética em rede. Em primeiro plano estão as micronarrativas relativas às histórias de humor e aos relacionamentos humanos. Na sequência, o tom existencialista e a necessidade de reconstruir o discurso das críticas sociais do cotidiano. A Figura 1 destaca esses quatro temas mais recorrentes na produção:

Figura 1 - Categorias temáticas mais recorrentes

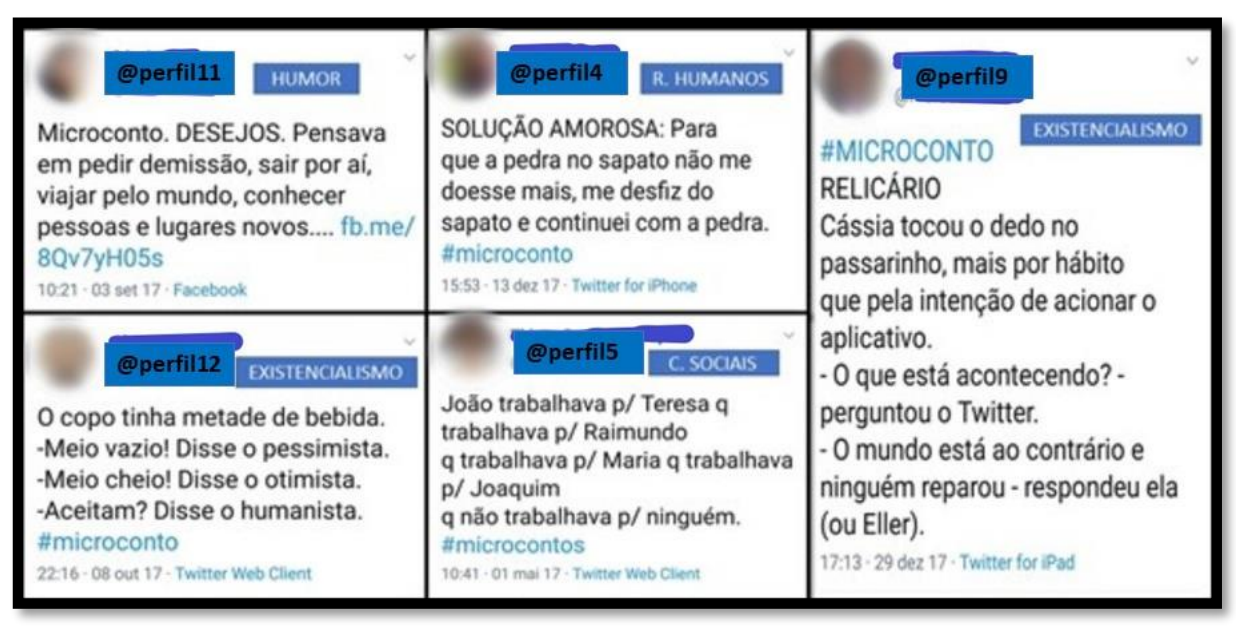

Fonte: Os autores do artigo e da pesquisa.

Em outra perspectiva, a morte, as cenas triviais do cotidiano e as relações construídas em ambientes de rede compõem o quarto plano descritivo das narrativas. Os metatextos e o erotismo se equiparam como interesses do quinto plano de expressão dos textos, seguidos pelo interesse na ficção científica, conforme a sistematização apresentada na Figura 2. 
Figura 2 - Demais categorias temáticas

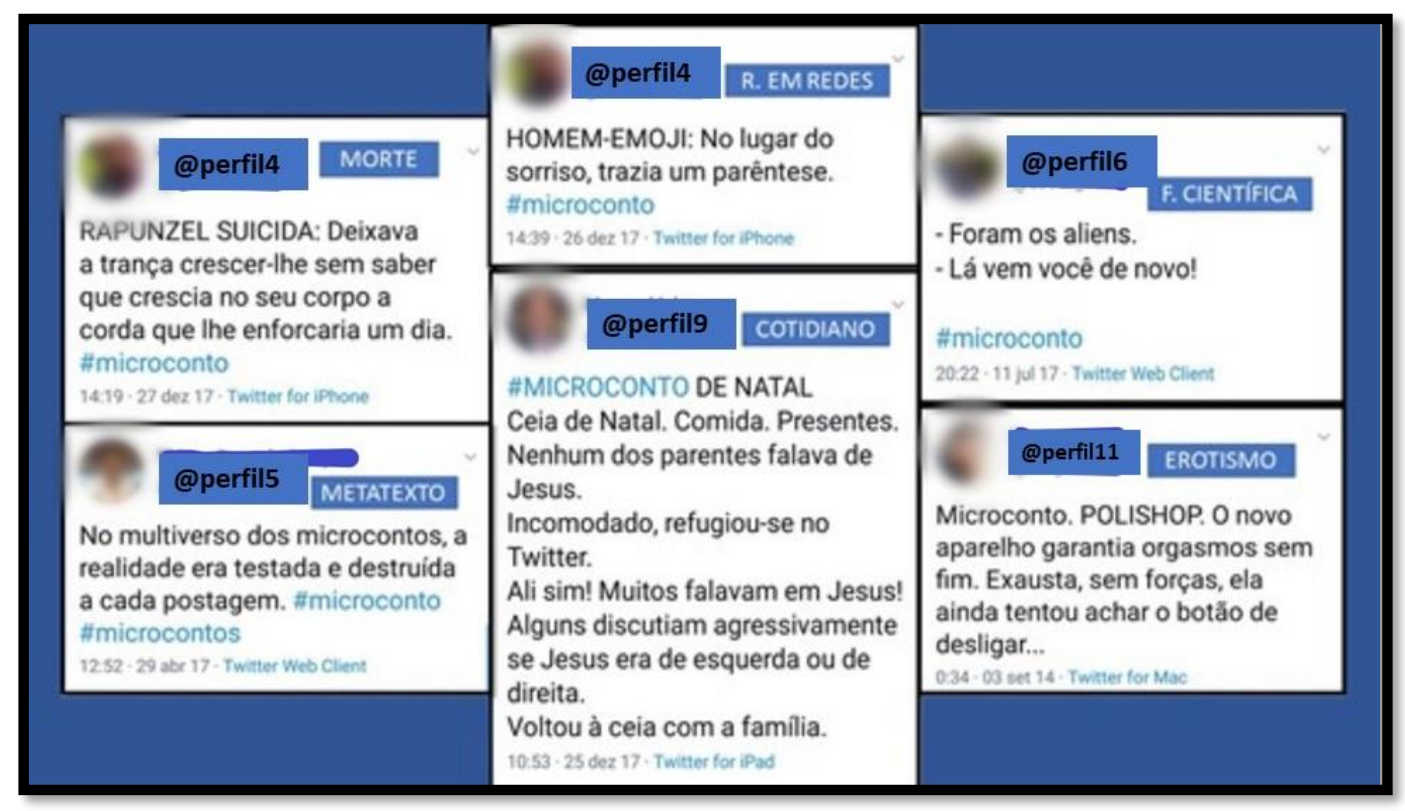

Fonte: Os autores do artigo e da pesquisa.

Na Figura 2, vemos um mosaico de seis categorias temáticas. Nos temas expressos nelas, percebemos a capacidade que a ficção possui de ratificar a "humanidade do homem", conforme Candido (2012). Dessa forma, a observação total das 10 categorias revela reverberações significativas na representação da vida humana através das composições literárias que os sujeitos constroem em seus microcontos. Elas nos permitem perceber como essas nuances se abrigam facilmente em meio aos usos convencionais do Twitter.

Esses desdobramentos temáticos produzidos nas práticas sociais de escrita dos microcontos indicam uma riqueza que ecoa como um leque variado de representações. Em cada categoria temática se desdobra uma espécie de malha movente que expande as possibilidades de leitura, intervenção, compreensão dos textos. É nesse sentido que a identificação e ordenamento dessas informações contribuem para a análise dos microcontos produzidos pelos perfis selecionados.

\section{As repercussões}

Os microcontos apresentados nas Figuras 1 e 2 representam uma amostra do corpus total coletado ao longo da pesquisa. As estratégias e aprendizagens de cada 
sujeito em relação à construção de micronarrativas e suas intencionalidades nessa rede social são reveladas nesses textos através da exteriorização da produção escrita. Algumas escolhas e decisões estéticas acionadas pelos sujeitos revelam como se constrói, em rede, um processo de educação para as sensibilidades. O texto incompleto, a indexação de link para a continuidade do plano narrativo, o controle sobre o comportamento leitor através da condução narrativa por movimentos de extensão, expansão, migração, imersão em rede, a antropofagia, a intertextualidade, os recursos expressivos de linguagem, o trocadilho, as molduras, dentre outros, são estratégias exploradas intencionalmente pelos sujeitos.

No entanto, além das aprendizagens relacionadas à própria escrita dos textos, isto é, da narrativa em si mesma, é importante compreender os aspectos relativos à natureza dessa produção em rede. A produção literária que ocorre no Twitter está sendo construída, conforme um dos criadores dessa rede social — Jack Dorsey —, em “uma plataforma de comunicação” (MUÑOZ e RIVEIRO, 2009). Por isso, destacamos como essas micronarrativas produziram repercussões no Twitter, as quais são nomeadas de engajamentos pela própria plataforma. Podemos identificar três naturezas distintas de engajamento, as quais revelam diferentes formas de interação e associação aos conteúdos produzidos: curtida, retweet e comentário.

Para fins ilustrativos, podemos destacar como referência as métricas alcançadas por 3 dos 5 microcontos reproduzidos na Figura 1: o microconto do @perfil11, pertencente à categoria temática Humor e os textos existencialistas do @perfil9 e@perfil12. Os dados da interação desses microcontos estão reproduzidos, abaixo, no Quadro 1:

Quadro 1 - Levantamento das métricas por microconto

\begin{tabular}{|cccc|}
\hline Microcontos & Curtidas & Retweets & Comentários \\
\hline @perfil11 & 00 & 00 & 00 \\
@perfil9 & 15 & 05 & 01 \\
@perfil12 & 27 & 03 & 02 \\
\hline
\end{tabular}

Fonte: Os autores do artigo e da pesquisa.

De acordo com as métricas acima, o texto que mais conseguiu engajamento em relação à quantidade de curtidas foi o microconto de autoria do@perfil12 que, 
em relação aos demais perfis, não chega a ser o que possui maior número de seguidores, computando 5.886. Tal elemento nos leva a uma segunda consideração: a quantidade de seguidores, no que se refere às produções literárias, não está diretamente associada com o sucesso dos conteúdos produzidos, visto que o texto produzido pelo@perfil11 não gerou engajamento ainda que esse perfil possua um total de 10,4 mil seguidores. As duas leituras acima, corroboram, então, para a compreensão de que no Twitter os laços afetivos não estão em primeiro plano no engajamento produzido em relação às postagens, mas o próprio conteúdo.

No entanto, além dos dados diretamente gerados no Twitter, há outros aspectos que precisam ser considerados na observação das interações produzidas. Conforme aparece na reprodução do microconto do @perfil11, na Figura 1, o tweet desse microconto apresentou uma característica distinta: um link para a continuidade da micronarrativa no Facebook. Ao seguirmos esse link, encontramos novas e diferentes métricas para esse texto. É possível contabilizar, no post do microconto no Facebook, 15 comentários, 10 compartilhamentos e 166 reações.

A repercussão é muito diferente daquela mapeada dentro do Twitter. Dessa composição podemos depreender algumas observações: a) embora, no primeiro momento, o tweet aponte para a ausência de engajamentos, esse dado pode ser interpretado de forma simetricamente inversa, pois a ausência de engajamentos no Twitter, ao invés de significar a falta de identificação e validação dos seguidores, indica uma compreensão completa da estratégia de construção narrativa do perfil e uma consequente obediência a ela; b) se a narrativa não se conclui no seu local de origem - o Twitter - também não é nele que os traços de interação em rede irão se materializar.

Essa leitura também permite constatar que há, na estratégia de expansão e migração entre redes construída pelo@perfil11, uma experiência de aprendizagem sobre a escrita literária em rede, uma pedagogia própria para a produção de engajamentos e visibilidade. Percebemos que não apenas o microconto se constrói em uma narrativa movente, como a própria ação de leitura também. Os números no Facebook, ambiente onde a narrativa se conclui, demonstram engajamento e validação. Embora não seja possível confirmar que todos os perfis interagentes no Facebook 
tenham chegado à postagem através do link do tweet, esse é um dos caminhos que pode ser hipoteticamente considerado e mostra comportamentos aprendentes e produtivos de elaboração, recepção e interação com os conteúdos estético-literários em rede.

No microconto de autoria do@perfil9, além das 15 curtidas e 3 retweets, notamos a presença de comentários de@interagente1 e @perfil10. Nas métricas, consta apenas 1 comentário em função do percurso de conversação realizada. O que se destaca nas interações registradas é a recepção positiva dos seguidores manifestada nos comentários de incentivo e aprovação. Há dois comentários registrados, o primeiro é do @interagente1 que interage com o incentivo valorativo “Adorei!”, no qual demonstra aprovação do conteúdo produzido e identificação. Já a segunda interação, do@perfil10, foi realizado em efeito dominó. Está conectado ao comentário de@interagente1, validando, em segundo nível, a produção que originou a conversa, isto é, o microconto. Em seu comentário, o @perfil10 escreve positivamente "Sabe que sabe!", reforçando a avaliação feita anteriormente.

Em relação às repercussões do microconto do @perfil12, notamos que o diálogo se expande com interações que criam desdobramentos a partir da narrativa. A interação funciona como uma espécie de hipertexto que se constrói simultaneamente. Essa possibilidade interativa em tempo real faz do Twitterainda mais veloz, fluido e instantâneo e cria para a produção literária uma atmosfera na qual os produtos estéticos possuem, na incompletude e na abertura, um elemento constituinte, latente, potencial. É uma parte integrante de sua natureza e gênese em rede, bem como das ações dos sujeitos que demonstram aprendizagens sobre esse ambiente e sobre a própria produção.

A interação em tempo real funciona como uma espécie de autorização dos sujeitos comuns, os quais não carregam o emblema oficial de escritores, nem o largo reconhecimento institucional de suas produções literárias. No Twitter, a escrita literária incorpora todas as possibilidades, estruturas e conexões da plataforma que a abriga. Podemos observar, na interação reproduzida, um exemplo de como a produção de microcontos no Twitter se mistura, se amálgama aos outros usos que os sujeitos fazem dessa rede social a ponto de permitir que autores e leitores comuns, não reconhecidos 
editorialmente como escritores, se sintam autorizados a produzir, dialogar, interferir, compartilhar seus textos, percepções, experiências, epifanias. Observemos esse elemento na repercussão do microconto do@perfil12:

Figura 3 - Repercussão do microconto 03

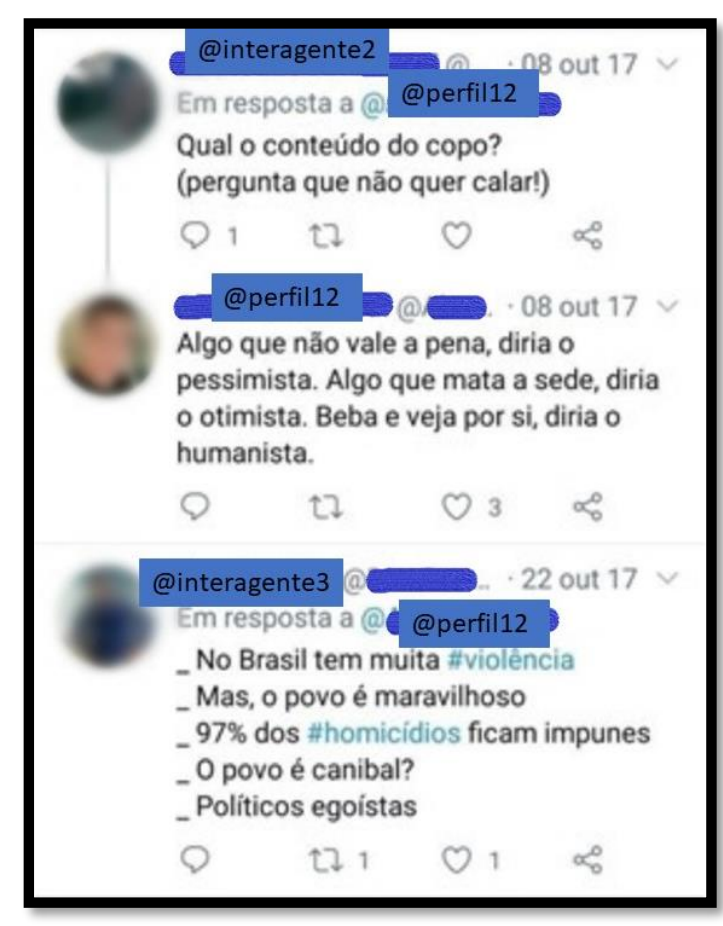

Fonte: Os autores do artigo e da pesquisa.

No microconto existencialista do@perfil12, a natureza aberta do texto literário se manifesta de forma mais produtiva através da remixagem, da retextualização da produção coletiva motivada pela interação, a qual instiga o autor a agregar ao texto original as contribuições advindas dos comentários dos seguidores do perfil, agenciando a aprendizagem de formas colaborativas de produção. Assim, o Twitter se transforma naquilo que Santaella e Lemos (2010) chamam de ágora digital global. Na Figura 3, vemos o registro da interação de dois dos seguidores do perfil pesquisado: @interagente2 e @interagente3. O que se destaca é que a intervenção do @interagente2 constrói um questionamento que funciona como um propulsor da continuidade do processo criativo do@perfil12, confirmando o pensamento de Lévy (1997, p. 135-6) de que as produções em ambiente digital passam a contar com "[...] a participação nas obras daqueles que as provam, interpretam, exploram ou leem. [...] 
o 'espectador' é chamado a intervir diretamente na atualização [...] de uma sequência de signos ou de acontecimentos".

A partir da pergunta feita “Qual o conteúdo do copo?”, o processo de criação do microconto se reinicia evidenciando as potencialidades que o engajamento possui de interferir diretamente na narrativa. Vemos, no comentário de resposta do autor, mais um lance de escada para a história, uma segunda conversa construída para os personagens em resposta à provocação leitora eficiente. Ao fim, temos dois ou mais microcontos se considerarmos a fragmentação, a integralidade e os percursos de leitura do tweet. Tais comportamentos de produção estética, segundo Santana (2014, p. 100) advêm das "especificidades do Twitter e sua arquitetura organizacional, que permitem que os tweets tenham alcance em escala mundial". Eles constroem modos de colaboração intelectual em rede que, de acordo com Santaella e Lemos (2010, p. 63), "caracterizam uma nova etapa de evolução nos processos de inteligência coletiva".

Por outro lado, na intervenção realizada pelo@interagente3, o foco não é mais a construção da mesma narrativa, mas a proposição de outro microconto, de autoria do seguidor, no qual ele se utiliza dos mesmos recursos formais do tweet original: o diálogo, o pessimismo, o otimismo e a relatividade dos fatos, inserindo na criação do outro a sua própria micronarrativa, abolindo a distinção tradicional entre produção e consumo, conforme Bourriaud (2009). Esses comportamentos levam os engajamentos a um nível mais produtivo de elaboração de conteúdos, uma vez que não se limitam a validar os materiais já produzidos, mas inserem contribuições que os modificam e ou ampliam coletivamente. Assim, encontramos nos textos analisados vários componentes da forma narrativa microconto, bem como aspectos relativos à produção em rede. Notamos os caminhos de conexão, de exteriorização da escrita e de seu compartilhamento, os quais perpassam pela twitteratura, isto é, a produção literária no Twitter, e por processos de aprendizagem e educação das sensibilidades em rede. 


\section{Considerações finais}

O estudo desenvolvido nos permitiu elaborar conclusões sobre o fenômeno investigado. Estão entre as principais conclusões geradas: a) as experiências de escrita colaborativa e/ou compartilhada permitem e estimulam a reelaboração dos textos em uma ação conjunta com o leitor; b) o Twitter oferece a expansão da capacidade de exteriorização dos processos de escrita, uma vez que a conexão em rede e a liberdade de compartilhamento permitiram aos sujeitos a potencialização das trocas, dos diálogos reflexivos e metalinguísticos sobre a própria experiência de escrita literária; e c) a externalização dos processos individuais e coletivos de escrita literária revelam gestos de aprendizagens em rede e o agenciamento de pedagogias de escrita no Twitter.

Tais conclusões nos permitem constatar que os comportamentos dos sujeitos dentro dos perfis selecionados apontaram o acionamento intencional de estratégias, metodologias, recursos e estilos próprios para a produção estética, bem como o exercício de testagem das possibilidades de escrita, dos recursos da plataforma, o que levou, simultaneamente, ao domínio dos elementos fornecidos e sua expansão quando não eram suficientes. Dessa forma, a partir das análises apresentadas acerca dos perfis, das categorias temáticas e dos microcontos, destacamos a conclusão de que a twitteratura, isto é, a produção de conteúdo literário no Twitter, contém aspectos pedagógicos importantes para as práticas de leitura e escrita de microcontos.

Por fim, podemos concluir que o comportamento de experimentação literária dos perfis analisados dialoga com a capacidade que a escrita literária no Twitter possui para promover a educação das sensibilidades através do acionamento de estratégias estéticas e de recursos do ambiente em rede. Esse comportamento indica e oferece uma perspectiva privilegiada para pensar o texto literário também através da experimentação, da consciência prática das estratégias de sua produção e dos canais de comunicação e interação nos quais pode circular. Vista dessa forma, a produção de microcontos no Twitter contém e constrói pedagogias, promovendo um processo de aprendizagem responsável pela articulação entre antigas e novas práticas sociais sustentadas por uma configuração sócio-histórico-cultural: a cibercultura. 


\section{Referências}

AMARAL, A.; MONTARDO, S. P. Pesquisa em Cibercultura e Internet: Estudo exploratório comparativo da produção científica da área no Brasil e nos Estados Unidos. In: Anais... $2010 . \quad$ Disponível em: http://www.intercom.org.br/papers/nacionais/2010/resumos/R5-2639-1.pdf. Acesso em: 20 out. 2017.

ASSMANN, H. Reencartar a educação. Rumo à sociedade aprendente. Petrópolis:Vozes, 1998.

BAKHTIN. M. Questões de Literatura e de estética: a teoria do romance. 6. ed. Hucitec/Annablume, 2010.

BOURRIAUD, N. Pós-produção como a arte reprograma o mundocontemporâneo. Trad. Denise Boltimann. São Paulo: Martins, 2009.

CANDIDO, A. A Literatura e a formação do homem. Remate de males, Campinas (SP), 2012. Disponível em: revistas.iel.unicamp.br/index.php/remate/article/viewFile/3560/3007. Acesso em: 15 out. 2021. DOI: https://doi.org/10.20396/remate.v0i0.8635992

COUTO, E. S. Corpos voláteis, corpos perfeitos. Pedagogias e políticas do pós-humano. Salvador: EDUFBA, 2012.

COUTO, E. S. Pedagogias das conexões: compartilhar conhecimentos e construir subjetividades nas redes sociais digitais. In: PORTO, C.; SANTOS, E. (Org). Facebook e educação: publicar, curtir, compartilhar. Campina Grande: EDUEPB, 2014. p. 47-65.

CRESWELL, J. W. Projeto de pesquisa: métodos qualitativo, quantitativo e misto. 3. ed. Trad. Magda Lopes. Porto Alegre: Artmed, 2010.

ELM, M. S. How do various notions of privacy influence decisions in qualitative internet research? In: MARKHAM, A. N.; BAYM, N. Internet inquiry. Conversations about method. Los Angles: Sage, 2009. p. 69-87.

FREEMAN, L. The development of social network analysis. Vancouver: Empirical Press, 2004.

GONZÁLES GUTIÉRREZ, L. La narración colaborativa em @Elhombredetweed. Un análisis pragmático para el estudio de la literatura digital. Teknokultura, v. 15, n. 1, p. 5-22, 2018. DOI: http://dx.doi.org/10.5209/TEKN.57192.

HINE, C. Virtual Ethnography. London: Sage, 2000.

JONES, S. Studying the Net. Intricacies and Issues. In: JONES, S. (ed). Doing Internet Research. Critical Issues and Methods for Examining Net. London: Sage, 1999.

LASTA, E.; BARRICHELLO, E. M. R. Proposta de uma matriz de analise de estrategias sociotecnicas de visibilidade e legitimidade presentes em blogs corporativos. Intercom RBCC, São Paulo, v. 36, n. 1, p. 249-268, jan./jun. 2013. Disponível em: http://www.scielo.br/pdf/interc/v36n1/13.pdf. Acesso em: 20 abr.2014. 
LÉVY, P. Cyberculture. Paris: Éditions Odile Jacob, 1997.

LÉVY, P. Tecnologias intelectuais e modos de conhecer: nós somos o texto. Trad. Celso Cândido. MIDIARTE - Website do Programa Avançado de CulturaContemporânea da URFJ. 2003. Disponível em: http://www. pacc. ufrj. br/midiarte/teste2/ conteudo2. php.

LIMA, E. G. Da literatura à moda antiga à literatura digital: "isto matará aquilo?”. In: LIMA, E. G. Leitura e Literatura do centro às margens: entre vozes, livros e redes. Campinas: Pontes Editores, 2016. p. 76-94.

LOURO, G. L. (Org). O corpo educado. Pedagogias da sexualidade. Belo Horizonte: Autêntica, 2018.

LUIJPEN, W. Introdução à fenomenologia existencial. São Paulo: EPU, 1973. 400p.

MARCUSCHI, L. A. Gêneros textuais: configuração, dinamicidade ecirculação. Gêneros textuais: reflexões e ensino, v. 2, p. 23-36, 2005.

MONTIEL, D. E. Tuiteratura: la frontera de la microliteratura en el espaciodigital.Iberi@ l, n. 5, p. 05-05, 2015.

MORAES, R.; GALIAZZI, M. C. Análise textual discursiva. Ijuí: Editora Unijuí, 2016.

MUÑOZ, R.; RIVEIRO, A. "Entrevista: Jack Dorsey", El País, 2009. Disponível em: http://tecnologia.elpais.com/tecnologia/2009/03/25/actualidad/1237973279_850215.ht ml. Acesso em: 10 fev. 2016.

NAVARRO, P.; DIAZ, C. Análisis de contenido. In: DELGADO, J. M.; GUTIERREZ, J. Métodos y técnicas cualitativas de investigación em ciências sociales. Madrid: Sintesis, 1994.

OLIVEIRA, S. A. Um circuito de poesia na mídia digital: breves notas sobre o movimento POETRIX. In: CORDEIRO, V. M. R.; GONÇALVEZ, L. S. M.; LIMA, E. G. (Orgs.). Leitura e Literatura do centro às margens: entre vozes, livros e redes. Campinas: Pontes Escritores, 2016.

RECUERO, R. Redes sociais na internet. Porto Alegre: Sulina, 2011.

RECUERO, R.; BASTOS, M.; e ZAGO, G. Análise de Redes para Mídia Social. Porto Alegre: Sulina, 2015.

RECUERO, R.; ZAGO, G. "RT, por favor": considerações sobre a difusãode informações no Twitter. Fronteiras-estudos midiáticos, v. 12, n. 2, p. 69-81, 2010.

SAGREDO, A. S. Literatura y posmodernidad: sobre interactividad yescritura hipertextual. Castilla. Estudios de Literatura, n. 3, p. 365-384, 2012.

SANTAELLA, L.; LEMOS, R. Redes sociais digitais: a cognição conectivado Twitter. São Paulo: Paulus, 2010.

SANTANA, C. L. S. E. Visibilidade mediada: estratégias e ações docentes no Twitter'. 2014. 257 f. Tese (Doutorado em Educação) - Universidade Federal da Bahia, Salvador. Biblioteca Depositária: Biblioteca Anísio Teixeira-FACED, 2014. 
SANTANA, C. L.; COUTO, E. S. Estratégias de visibilidade e ações docentes no twitter. Revista Educação (UFSM), v. 42, n. 21, pp. 435-450, maio/ago. 2017. Disponível em: https://periodicos.ufsm.br/reveducacao/article/view/22553/pdf. Acesso em: 28 set. 2020.

SILVA, T. T. (Org.) Identidade e diferença. A perspectiva dos estudos culturais. Petrópolis: Vozes, 2014.

RECEBIDO: $19 / 12 / 2021$

APROVADO: $30 / 08 / 2021$

RECEIVED: $12 / 19 / 2021$

APPROVED: 08/30/2021

RECIBIDO: $19 / 12 / 2021$

APROBADO: $30 / 08 / 2021$ 